\title{
Study of Self Concept In Relation To Family
} Environment among Adolescents

\author{
Lakshmi Arun ${ }^{1}$, Dr. Ravikumar M B ${ }^{2}$, Arushi J Makhija ${ }^{3}$, \\ Shonali Christine Barreto ${ }^{4}$, Vidhya Vishwanathan ${ }^{5}$
}

\section{ABSTRACT:}

This study examines Self-concept in relationship with Family environment among adolescents. The study involved a total of 137 adolescents in the age group from 17-19 years, Adolescents's Self Concept Scale - CSCS and CYDS Family Environment Scale was used to measure selfconcept and family environment among adolescents. Then the data was scored and statistically analyses by using t-test and correlation. The result of the study revealed that there is no significant difference between male and female adolescents in their self-concept, and also there is no significant difference between male and female in their family environment. There is a highly significant positive correlation between self concept and family environment among adolescents.

Keywords: Self-concept, Family environment, Adolescents.

\section{INTRODUCTION:}

The process of adolescence is a period of preparation for adulthood during which time several key developmental experiences occur. Besides physical and sexual maturation, these experiences include movement toward social and economic independence, and development of identity, the acquisition of skills needed to carry out adult relationships and roles, and the capacity for abstract reasoning. While adolescence is a time of tremendous growth and potential, it is also a time of considerable risk during which social contexts exert powerful influences.

The feelings one develops about oneself are formed quite early in life and are modified by subsequent experiences.

\footnotetext{
${ }^{1} \mathrm{Msc}, \mathrm{PhD}$, Assistant professor, Mount Carmel college, Bangalore, KarnatakaArun

${ }^{2}$ ART Counsellor, MIMS, Mandya, Karnataka.

${ }^{3}$ Shonali Christine Baretto, Vidhya vishwanathan, B A student, Mount carmel college Bangalore, Karnataka.
} 
The fact that the significant people who come and go in a child's life leaving an edible mark on how he views himself / herself, are many and varied. It leads us to believe that the basic factor in the development of self-image is flexibility. Adolescence is a period of life in which the sense of self changes profoundly. Family is the first school of the child. Family plays an important role in the development of the child. Family is the social agency, which develops the skill of socialization in the child. According to Eitzen (2003) "Family is a construct of meaningful relationships". This is perhaps the most important point for the educational practitioner to keep in mind that the child's self concept is not unalterably fixed, but is modified by every life experience, both in and out the classroom, at least through the maturing years. His / her present concept of self, and his / her relationship to the other children and to the teacher, is profoundly affected by such factors as his social-class membership, family structure, parental behavior, ethnic background, religion and the language spoken in the home. It is very interesting to find that how the factors outside the classroom affect the child's self concept.

Self concept is a central theme around which a large number of major aspects of the personality are organized. It's importance stems from it's influence over the quality of a person's behavior and his adjustment to life and situations.

According to Rogers (1951), Self concept or self structure is "an organized configuration of perception of the self which are admissible to the awareness". It is the nuclear concept of personality, conceived as a result of interaction of the individual with his environment. The self concept measured by this scale refers to a set of relatively stable self-attitudes, which are not only descriptive, but also evaluative. Children learn the ways of people in their culture by participating in cultural tasks and activities (Ogbu, 1988). The family is the primary unit through which customs, beliefs, habits, values, and modes of behavior are transmitted from one generation to the next through the process of socialization (Saraswathi \& Dutta, 1988; Tandon, 1981). For children, the most important familial influence is the quality of the home environment for academic learning and parental involvement. Researchers report strong correlations between characteristics of the home environment (Alyward 1997; Molfese, Di Lalla, and Bunce, 1995). Bayder and Brook-Gunn (1991) found that grandmother care is related to higher cognitive development and fewer behavioural problems among preschoolers. Moreover, there is reason to believe that grand parenting may have particularly strong effects on child socialization. Whitney (1999) found that family environment appears to contribute to the well being in present as well as future life of the child. Lawanu Bordoloi(2012) explored on SelfConcept of Hostellers and Non-Hostellers result indicated that the hostellers always form a good and positive self concept as they have need to face with many problems. But there was a significant difference between the hostellers and non- hostellers on various dimensions of selfconcept.

Amit Kauts and Balwinder Kaur (2003) Evaluated children's behaviour in relation to family environment and technological exposure at pre primary stage. The findings of the study reveal 
that children's behaviour is better in families with good family environment than in families with poor family environment. Rajesh Kumar and Roshan Lal (2014) studied academic achievement in relation to family environment among adolescents which revealed that adolescents experiencing healthy family environments are found to have higher academic achievement in comparison to children belonging to low family environment.

\section{OBJECTIVES:}

1. To study the self concept of adolescents

2. To study the family environment of adolescents

3. To study the relation between self concept and family environment

\section{METHOD}

\section{Hypotheses}

1. There is significant difference in the self concept of male and female adolescents.

2. There is significant difference in the family environment of male and female adolescents.

3. There is positive effect of the self-concept and family environment among adolescents.

\section{Sample:}

A convenient random sampling technique was used for present sample of 137 subjects. The age ranges between 17 to 19 years old, of which 83 are girls and 54 are boys. The subjects were selected from various colleges of Bengaluru city.

\section{Measures}

The following tools were used for obtaining data

CYDS Family Environment Scale: is a pencil paper test. It is based on the Family Environment Scale by Moos and Moos (1974). Although the concept of dimensions has been taken from Moos' scale, all the subscales have been operationally defined with certain modifications of original definitions. It has five sub-scales which are important in the psychological world of adolescence. They are: Support, Beliefs about Purpose, Beliefs about Development, Deviant Beliefs, beliefs About Family.

\section{S.P. Ahluwalia's Children Self Concept Scale}

This measure produces six subscales. The score for each subscale is calculated by summing responses to the individual items. Sub scales are Behaviour, Intellectual and school status, 
Physical appearances and attitudes, Anxiety, Popularity, Happiness and satisfaction And one lie scale. A high score on a scale is presumed to indicate a favorable self concept.

\section{PROCEDURE:}

To study self concept and family environment among adolescents, the researcher took permission and collected data from the selected Bangalore colleges like Mount Carmel (PU) College, Maharani Arts and Science College, St.Joseph's College, REVA College, Deeksha School, Lal Bahadur Shastri Government First Grade College, Hymamshu Jothi Kala Peetha, Ramaiah Institute of Technology. The participants were given appropriate instructions and asked to indicate their responses in the respective sheets given to them. Whenever they had doubt in understanding items, the test administrator clarified their doubts in their local language. Data collection was done in one session and a session lasted for about 50-60 minutes approximately. Then the data was scored and statistically analysed by using descriptive, $\mathrm{T}$ test and correlations.

\section{RESULTS AND DISCUSSION}

Table No 1. Shows mean, SD and t values for self-concept and family environment of adolescents.

\begin{tabular}{|llllllll|}
\hline Variable & Gender & $\mathbf{N}$ & Mean & $\begin{array}{l}\text { Std. } \\
\text { Deviation }\end{array}$ & t & df & P \\
Self-concept & Male & 54 & 89.76 & 10.062 & 1.299 & 135 & .196 \\
& Female & 83 & 87.60 & 9.112 & & & \\
Family & Male & 54 & 51.83 & 13.102 & -.231 & 135 & .818 \\
Environment & Female & 83 & 52.31 & 11.021 & & & \\
\hline
\end{tabular}

Table No 1. Shows mean, SD and t values for self-concept of adolescents. Self-concept of male adolescents (Mean=89.76; $\mathrm{SD}=10.062$ ) and female adolescents (Mean=87.60; SD=9.112) $(\mathrm{t}=1.299 ; \mathrm{p}<.196)$ indicating no significant difference. It can be said that male and female adolescents has no difference on self-concept. Therefore, formulated $\mathbf{H}_{\mathbf{1}}$ there is significant difference in the self-concept of male and female adolescents, was not accepted.

Family environment of male adolescents (Mean=51.83; $\mathrm{SD}=13.102)$ and female adolescents (Mean=52.31; $\mathrm{SD}=11.021)(\mathrm{t}=-.231 ; \mathrm{p}<.818)$ indicating no significant difference. It can be said that male and female adolescents has no difference on family environment. Therefore, formulated $\mathbf{H}_{2}$ there is significant difference in the family environment of male and female adolescents was not accepted. This finding gets its support from the fact that the first learning of the child commences at his/her home by his/her family. The early years of rapid development of 
children depends largely on their family environment. So, the impact of family environment on a child's behavior is ever lasting.( Amit Kauts., Balwinder Kaur (2003)

Table No 2. Shows mean, SD and $r$ values for self-concept and family environment of adolescents.

\begin{tabular}{|llclll|}
\hline Variable & N & Mean & Std. Deviation & r & sig \\
Family & 138 & 87.81 & 12.111 & .328 & .000 \\
environment & & & 12.603 & & \\
Self-concept & 138 & 51.75 & 12.603 \\
\hline
\end{tabular}

Table No 2. Shows mean, SD and $\mathrm{r}$ values for self-concept and family environment of adolescents. Self-concept of adolescents (Mean=87.82; $\mathrm{SD}=12.111)$ and family environment of adolescents $(\mathrm{Mean}=51.75 ; \mathrm{SD}=12.603)(\mathrm{r}=.328 ; \mathrm{p}<.000)$ indicating highly significant positive correlation. It can be said that self-concept and family environment for adolescents were highly positive correlation. Therefore, formulated $\mathbf{H}_{3}$ there is there is positive effect of the self-concept and family environment among adolescents, was accepted.

In the present study the results reveal that male and female adolescents having no significantly difference of self-concept and family environment. The self-concept and family environment of adolescents indicated highly positive correlations. Whitney (1999), Lawanu Bordoloi (2012), Amit Kauts and Balwinder Kaur (2003), Rajesh Kumar and Roshan Lal (2014) have revealed similar of all these studies have supported the findings of the studies.

\section{CONCLUSIONS}

1. Male and female adolescents have no difference on self-concept.

2. Male and female adolescents have no difference on family environment.

3. Self-concept and family environment for adolescents were positively correlated.

\section{REFERENCE}

1. Ahluwalia, S. P. (1986). Children's Self Concept Scale. Faculty of Education, University of Sagar, M.P.

2. Al-Zyoudi Mohammed (2007). Gender differences in Self-Concept among Adolescents with low vision. International Journal of Special Education, 22(1):132-136

3. Amit Kauts and Balwinder Kaur. (2003). A Study of children's behaviour in relation to family environment and technological exposure at pre primary stage. A Study of Children's Behavior 1(2), 2003-11.

4. Eitzen (2003). Social Problems - Del Mar College, Family

5. Hundekar and Khadi (2013). Department of human development and family studies, Dharwad, Karnataka, Journal on Agriculture Science, 26(4), 547-550. 
6. Jagpreet Kaur, J. S. Rana and Rupinder Kaur. (2009). Home Environment and Academic Achievement as Correlates of Self-concept among Adolescents, Studies on Home and Commumity Science, 3(1)

7. Lau Kit Ling. (1995). Family Relationship, Self-concept, and Delinquency among Hong Kong Adolescents, M. Phil. Thesis in Education, The Chinese University of Hong Kong.

8. Lau Sing, Kwok Lai-Kuen (2000). Relationship of family environment to adolescent's depression and self-concept, Social Behavior and Personality,30(5), 887-889.

9. Lawanu Bordoloi (2012). A Comparative Study of Self Concept of Hostellers and NonHostellers, International Journal for basic science and social science, 1(2), 46-49.

10. Lyon Mark, A (1993). Academic Self-Concept and its Relationship to Achievement in a Sample of Junior High School Students, Educational and Psychological Measurement, 53(1): 201-210.

11. Rachna Sharma (2014). A Study of Self Concept and Empowerment of Adolescent Girls, Asian journal of Multidisciplinary studies, 2( 1).

12. Rajesh Kumar and Roshan Lal. (2014). Impact of an Assertiveness Training on Self Concept among Adolescents, Indian Journal of Psychological Sciences 4(1),

13. Rath, Sangeeta, Nanda Sumitra. ( 2012). Adolescent's self-concept: Understanding the role of gender and academic competence, International Journal of Research Studies in Psychology 1(2), 63-71.

14. Saraswati, T. S and Dutta, R. (1988). Invisible Boundries: Grooming for Adult Roles, Northern Book Centre, New Delhi.

15. Sing Lau, Lai-Kuen Kwok. (2000). Relationship of family environment to adolescents' depression and self-concept, Social behavior and personality an international journal, 28(1) 41-50.

16. Tandon, T (1981). Process of transmission of values in the Indian Child, Socialization of the Indian Child, Concept Publishing, New Delhi, 11-30.

17. Weber, Angie D., (2001) influence of family environment on self esteem and hostility, Honors thesis, 253.

18. Whitney, A (1999). The Effect of Childhood Sexual Abuse and Family Environment on Present and Future Possible Selves (Self Concept), Dai 60(4), 1875. 